\title{
Cidade e políticas locais compensatórias
}

\section{The city and local compensatory local policies}

\author{
Yara VICENTINI*
}

\section{RESUMO}

A deficiência das políticas sociais tradicionais e dos investimentos públicos consolidou uma crescente pobreza da população na América Latina, trazendo ao debate o âmbito universalista ou seletivo das políticas urbanas sociais. Se, de um lado, as formas de seguridade social de cunho universalista estão mundialmente em crise, de outro, os programas de assistência social, dirigidos aos pobres, não são novidades. $\mathrm{O}$ que se configura como novo é o vínculo das estratégias orientadas a grupos-meta como expressão política das gestões urbanas. Às cidades, palco do embate social, cabe construir um nível de integração sócio-cultural e crescimento dos indicadores mínimos de qualidade e de distribuição de renda na América Latina, cujo modelo de crescimento e expansão contemporâneo coloca-se em um patamar diferenciado das cidades capitais européias, que com suas reformas urbanas contemporâneas conceituam as cidades como bem estratégico, promovendo intervenções urbanas pontuais, que alicercem formas de concentração de renda em níveis de consumo mais sofisticados ou de serviços pós-industriais. Discutese, como exemplo paradigmático no Brasil, a cidade de Curitiba que assimila o contexto das simulações urbanas em cidades mundiais sem ser, ela mesma, uma cidade mundial.

Palavras-chave: políticas sociais, cidade, gestão urbana, Curitiba

\begin{abstract}
Deficiency in traditional social policies and public investments has consolidated the increasing poverty of Latin American populations, bringing to the debate the universal or selective contexts of urban social policies. If on one hand, general social security systems are in crises all over the world, on the other hand, social assistance programs aimed at the poor are nothing new. What is new is the connection of strategies targeting meta-groups as a political expression of urban management. It is up to the cities, as stages of social struggle, to build a level of socio-cultural integration and the growth of basic quality indicators and income distribution in Latin America. Their contemporary growth and expansion model is on a different level in comparison to European capital cities which, with their contemporary urban reforms, develop a concept of city as a strategic asset, promoting localized urban interventions that support ways of income concentration in more sophisticated consumption levels or post-industrial services. This paper discusses Curitiba as a paradigmatic example in Brazil, a city that assimilates urban simulations from other cities of the world, without being a city of the world itself. Key-words: social policies, city, urban management, Curitiba.
\end{abstract}

\footnotetext{
* Doutora em Arquitetura. Professora do Departamento de Arquitetura e Urbanismo e ex-coordenadora do Doutorado em Meio Ambiente e Desenvolvimento da
} UFPR. 
A deficiência da política social e dos investimentos públicos gerou uma crescente pobreza da população na América Latina, trazendo ao debate o âmbito universalista ou seletivo das políticas sociais. Se, de um lado, as formas de seguridade social de cunho universalista estão mundialmente em crise, de outro, os programas de assistência social dirigidos aos pobres não são novidade. $\mathrm{O}$ que se configura como novo é o vínculo das estratégias orientadas a grupos-meta com a política econômica de ajustes estruturais e seu acoplamento funcional a essa política. Nesse sentido, de um modo geral, as estratégias de políticas sociais seletivas para a luta contra a pobreza são avaliadas como compensação social a um ajuste estrutural considerado necessário, apoiadas em um discurso de privatização, desregulamentação e descentralização do Estado. Expressam-se pelo conjunto de programas de assistência social e fundos em diversos países da América Latina, tais como os Fundos de Inversão Social, financiados pelo Banco Mundial. Estes fundos foram implantados e experimentados pela primeira vez na Bolívia, em 1985, por recomendação do Banco Mundial. Também se estabeleceram no Chile, Costa Rica, El Salvador, Honduras, Guatemala, Panamá, Nicaraguá, México, Peru, Uruguai, Venezuela e Brasil. ${ }^{1}$

Nesta medida, os países latino-americanos arcaram, ao longo das duas últimas décadas, com os pesados custos econômicos e sociais das experiências de ajustamento econômico e com a drástica redução de investimentos públicos em políticas sociais, agora afeitos a públicos metas dos programas sociais, que raramente se fez acompanhar por aumentos compensatórios dos investimentos privados. Em conjunturas locais de maior ou menor estagnação econômica, a vaga neoliberal têm produzido a necessidade de novas formas de enfrentamento e publicização da crise social que se expressa nas carências de grandes contingentes de população.

No âmbito das cidades é importante enfatizar que as políticas sociais urbanas interferiram na constituição das cidades e das metrópoles na América Latina já que, a precarização da infraestrutura urbana definiu grandes parcelas de população assentadas em extensas áreas de ocupação "ilegal", onde se implantam políticas de habitação e de infraestrutura social primárias e insuficientes, como formas compensatórias da exclusão da cidadania, do emprego e da própria cidade.
Os paradigmas presentes nas grandes reformas urbanas contemporâneas em curso nas cidades mundiais, não correspondem às possibilidades de investimento e renda geral da população na América Latina, resultando em assimilações incompletas de políticas de gestão urbana ou nos cenários mal acabados dos projetos urbanos, muito aquém das necessidades de investimentos em infra-estrutura básica e em políticas populares de recuperação da qualidade de vida urbana para as grandes cidades brasileiras.

Neste sentido, as discussões mais contemporâneas, sobre o urbanismo, enfatizam as transformações recentes relativas ao significado, caráter e a forma da cidade. Assiste-se a uma transformação, no pensamento e nas formulações sobre a configuração das cidades, dada as crescentes modificações na divisão técnica do trabalho e na divisão internacional da produção. Abandona-se, paulatinamente, nos meios acadêmicos e profissionais a "ideologia do plano", indistinto, modelo universal de um urbanismo racionalista. Por outro lado, perde-se a noção de corpo social, de utopia e de vanguarda, como vem apontando discussões recentes sobre estes conceitos. Ou como argumenta Harvey (1992) os velhos/novos territórios de segregação espacial étnicos e sociais, das grandes concentrações humanas/urbanas do final do século XX, testemunham a insensatez dos propósitos da razão. É sobretudo com estas indagações que faz sentido pensar a questão das cidades, nos termos contemporâneos.

Dentro desta perspectiva, vários são os enfoques que podem ser discutidos. Por um lado, a inauguração de um novo ciclo de assimilações do pensamento sobre a cidade no Brasil e na América Latina, inscrevendo a análise no debate das questões que hoje orientam posicionamentos teóricos-analíticos para a compreensão das sociedades contemporâneas, com termos como pós-modernidade, globalização e fragmentação. Por outro lado, implicam em alterações com origem na reestruturação econômica, em reorientações para o planejamento urbano, em novas formas urbanas e contextos político administrativos, na recomposição técnica do espaço e da ação política e da organização da sociedade.

Mais especificamente, referem-se às assimilações nos termos das transformações observadas nas denominadas cidades mundiais. É claro que se trata de uma adaptação de 
um modelo neo-liberal excludente, ou como o define Randolph (1996), um modelo de assimilação de uma nova matriz do poder social para a construção e consolidação de uma hegemonia ideológica amparada em uma retórica social e participativa. Ou seja, a transferência de modelos dos países centrais, para realidades latino-americanas inclui problemas adicionais, que vão desde as articulações sociais possíveis, até as dificuldades de transpor o abismo social e de integração e qualidade de vida nas cidades.

Transpor um consenso de reforma das cidades européias, perante a necessidade de entendê-las como um bem estratégico, remodelando este bem para formas de concentração em níveis de consumo mais sofisticados ou de serviços pós-industriais é fruto de um pensar histórico e cultural que não poderia ser transposto sem a necessária integração sociocultural e a expansão dos indicadores mínimos de qualidade e de distribuição de renda na América Latina, cujo modelo de crescimento e expansão contemporâneo coloca-se em outro patamar.

Porém, à medida que se avulta a discussão no panorama internacional, os ecos se fazem sentir em nosso país. Emprega-se uma gama de termos, como: renovação, revitalização, reurbanização, refuncionalização, requalificação, reestruturação, reabilitação, restauro, readaptação, para citar os mais freqüentes, que estão via de regra diretamente ligados à questão da revalorização de centros históricos ou de recuperação de áreas consideradas degradadas e ocupadas por população de baixa renda.

Em relação à Cidade de Curitiba o cenário não é diferente. Sem dúvida, trata-se de uma das cidades brasileiras que mais incorreu em ações planejadas para a definição de seu espaço urbano, considerando-se a proposta de Alfred Agache em 1943, que desenha a cidade considerando as áreas definidas por funções afeitas ao período (setores militar, educacional, cívico, industrial e de moradias, incluindo as de renda mais baixa) criando uma rede de avenidas de conformação radiocêntrica. ${ }^{2}$

Nos anos sessenta a cidade conta já com 360.000 habitantes e representa um pólo regional para o Estado. $\mathrm{O}$ processo de Planejamento Urbano, que então se inicia, pauta-se na idéia de modernização nos moldes do pensamento desenvolvimentista do período, cujo mote passa a ser a industrialização. Em 1965, o PDU - Plano de Desenvolvi- mento Urbano, definido pelo urbanista Jorge Wilheim e Arquitetos Associados, e apoiado por uma equipe local de acompanhamento, com técnicos da prefeitura e professores dos cursos de engenharia e arquitetura da Universidade Federal, constitui-se no embrião do IPPUC - Instituto de Pesquisa e Planejamento Urbano de Curitiba.

A partir de 1970, os projetos urbanos elaborados pelo órgão são colocados em prática, implantando o sistema de circulação e transportes de massa que redefine os traçados urbanos, com suas vias estruturais norte-sul e os corredores de circulação. É deste período a implementação da cidade industrial de Curitiba (1973), o início da construção de grandes parques em um sistema de recuperação das áreas deterioradas das antigas pedreiras e ocupação das áreas vazias e inundáveis da cidade, combinados com um projeto de revitalização do centro urbano nos moldes modernistas.

O conjunto de obras realizadas pelo PDU marca inexoravelmente a Cidade, mesmo considerando-se o lapso político partidário subsequente. Ao final da década de 80 a linha mestra de desenvolvimento da cidade é retomada, considerando que as críticas construídas no período já apontassem para a marginalização da população de baixa renda, agora habitantes dos municípios vizinhos na região metropolitana. Curitiba passa de um slogan de cidade modelo para o slogan de cidade ecológica, em um alinhamento com as transformações dos discursos sobre o urbano em nível mundial. Uma série de temáticas ambientais e programas específicos são então implementados (estações tubos, parques, memoriais), exacerbando uma cultura do consumo da cidade, agora objeto de intensa propaganda que vai, sintomaticamente, incluir a invenção de tradições urbanas através de uma simbologia pensada e de caráter rural - a folha de araucária, o pinhão desenhado nos cruzamentos, a folha da erva mate, os portais de migrantes, etc.

Como exemplo paradigmático, Curitiba assimila o contexto das simulações urbanas culturais das cidades mundiais sem ser, ela mesma, uma cidade mundial. Como uma antevisão do contexto contemporâneo das cidades em redes globais, coloca-se na perspectiva imagética dos projetos temáticos urbanos, mantendo seu forte viés rural e conservador. A cidade assim pensada é um fenômeno típico da cultura contemporânea, como uma mediação possí- 
vel entre as ações políticas, as práticas da comunicação e as intervenções urbanísticas, ou como enfatizaria Baudrillard (1985), um simulacro construído.

No entanto, a partir dos anos noventa, os apelos propagandísticos vem se esgotando com a constatação de que Curitiba e suas áreas urbanas refletem uma ocupação total da área física do município e as subsequentes invasões em áreas de proteção ambiental, dentro e fora dos limites do seu território. O novo recorte ambiental, por bacias hidrográficas, surpreende um conjunto de 26 municípios que assistem à degradação de seu ambiente, perante as dificuldades de financiamento e novos investimentos urbanos no Brasil ao final do século XX.

Talvez as análises pertinentes escapem a este texto, quando se referem à manutenção de uma imagem de cidade única e agora isolada de seu contexto regional metropolitano, dadas as dificuldades de assimilar os problemas ambientais e sociais do seu entorno dos quais até agora a cidade manteve-se afastada. Por outro lado, a imagem criada tinha que ser mantida mesmo que para isso fosse necessário a invenção de tradições, quando o antigo núcleo tropeiro foi banido do imaginário coletivo e substituído por uma cidade européia, baseada na mistura de migrantes alemães, italianos, poloneses, ucranianos e russos, conferindo uma identidade branca e européia construída ao largo dos migrantes nacionais. A invasão de terras e a ilegalidade dos loteamentos e das construções toma a Curitiba idealizada de surpresa, com um índice de 28\%, já em 2000, conforme dados do IPPUC (2000), de sua população em assentamentos irregulares, considerando aí as áreas ocupadas, os loteamentos clandestinos e as irregularidades construídas. Neste caso, as novas formas urbanas recorrentes constituem-se em precários projetos de reurbanização de favelas, inexoravelmente fadados à segregação visual, formal, cultural e social ou a condomínios fechados, muros de auto segregação que cercam a classe mais privilegiada da cidade, nas áreas de ligação com as manchas urbanas de municípios limítrofes da metrópole, separando-as das invasões bárbaras (figura 01).

A dificuldade assinalada é recorrente na compreensão das teorias urbanas contemporâneas frente à formula- ção de novas políticas e programas urbanos. Se durante todo o século XX no Brasil, os modelos e as teorias urbanas transferidas demonstraram sua fragilidade frente a uma análise mais detalhada, expondo dificuldades de assimilação em relação ao caráter social e político dos mesmos, como já discutiu amplamente Arantes (1998), novamente nos deparamos com tal situação, mesmo que colocada em termos contemporâneos.

Enfrentando a dicotomia estabelecida entre um modelo estratégico de planejamento das cidades mundiais, incluindo todos os ingredientes referenciais contemporâneos de volta ao urbanismo do lugar, frente à questão latino-americana das grandes cidades e seus espaços consolidados por décadas de exclusão, a consecução de novos modelos de gestão urbana, em uma nova matriz de acordos sociais, torna inerente mudanças profundas e não previstas nos modelos econômicos em pauta.

Estes projetos, desenvolvidos pelos governos municipal e estadual, consistiram em tentativas de modernizar e agregar áreas saneadas para a expansão da cidade, conquistando-as para a especulação imobiliária. Essa transformação urbana não se pautou exclusivamente pela expulsão das populações assentadas em áreas alagadiças, mas, incluiu a introdução de concepções "modernas" de planejamento, pois, de forma similar a de outras metrópoles brasileiras e internacionais, nas décadas de setenta e oitenta, o ideário do planejamento urbano, foi invadido por metodologias e sistemas de racionalização dos espaços urbanos, que engendraram modelos institucionais abstratos e ilegíveis à maioria da população, compatíveis com as novas formas de privatização do espaço.

As questões fundamentais sobre a cidade devem ser recuperadas, em torno de uma atuação urgente em habitação social e saneamento básico, com projetos de recuperação local que possam incluir a população, gerando o emprego urbano associado à gestão urbana, com tecnologias de soluções simples, sem serem simplórias, democráticas, sem serem populistas. Só assim o estatuto de cidadania e o novo instrumento legal urbano - o Estatuto da Cidade no Brasil - poderá ser construído na cidade, onde o conceito de cidadania inclui o direito ao emprego, a renda e a moradia urbana. 
FIGURA 01 - MAPA METROPOLITANO COM AS ÁREAS DE INVASÃO. MAP OF METROPOLITAN AREA SHOWING IRREGULAR OCCUPATION SITES

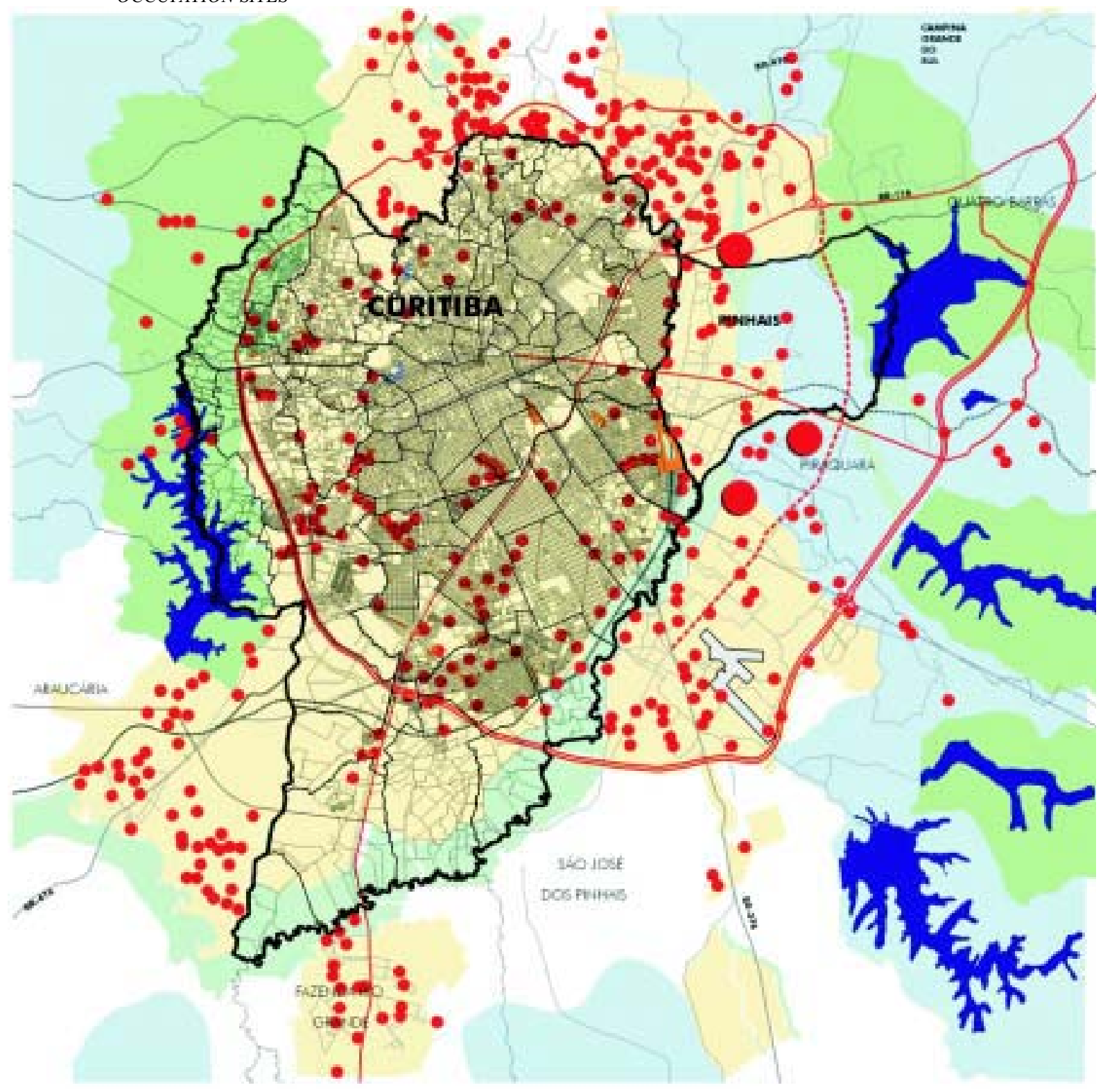

\section{OCUPAÇÕES IRREGULARES}

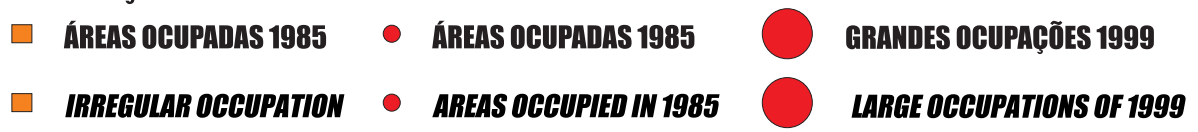

FONTE: PMDU, 1985; COMEC, 1999. SOURCE: PMDU, 1985; C. A. B. , 1999. 
VICENTINI, Y. Cidades e políticas locais compensatórias

\section{REFERÊNCIAS}

ARANTES, O. Urbanismo em fim de linha. São Paulo: Nobel/ Edusp, 1998.

. O lugar da arquitetura depois dos modernos. São Paulo: Studio Nobel, Fapesp-Edusp,1993.

. A sobrevida da arquitetura moderna segundo Habermas. Revista $A U$, n. 30, ano 6, p. 72-75, jun./jul. 1990.

BAUDRILLARD, A. Sombra da maioria silenciosa - o fim do social e o surgimento das massas. Tradução de: Suely Bastos, São Paulo: Brasiliense, 1985.

CASTELLS, Manuel. European Cities, the informational society, and the global economy. New left review, n. 204, p. 18-32, Mar./Apr. 1994.

La ciudad informacional: tecnologias de la información, reestruturación economica y el proceso urbano Regional, Madri: Alianza Editorial, 1995.

; BORJA, Jordi. As cidades como atores políticos. Revista novos estudos Cebrap, São Paulo, n. 45, p.152-166, jul. 1996.

FERNANDES, A.; GOMES, M. A. Cidade e urbanismo: história, teorias e práticas. MAU/UFBA, 1998.

FERNÁNDEZ, R. Modos de hacer ciudad. Buenos Aires: UBA/ FAUD UNMDP, 1996.

FRAMPTON, K. Historia crítica de la arquitectura moderna. Barcelona: GG., 1987.

GARCIA LAMAS, J. M. R. Morfologia urbana e desenho da cidade. Lisboa: Fundação Calouste Gulbenkean, 1993.

GOTTDIENER, M. A produção social do espaço urbano. Tradução de: G. G. de Souza, São Paulo: Edusp, 1993.

HABERMAS, J. O discurso filosófico da modernidade. Lisboa: Publicações Dom Quixote, 1990.

. A arquitetura pós-moderna. Novos estudos Cebrap, São Paulo, n. 18, 1987.
HARVEY, David. Condição pós-moderna. São Paulo: Edições Loyola, 1992.

IPPUC. Instituto de Pesquisa e Planejamento Urbano de Curitiba. Ocupações irregulares no município de Curitiba 1999/2000. Curitiba, 2000.

JACOB, J. The failure of town planning. USA: Pelican Book, 1964.

LEFEBVRE, H. O pensamento marxista e a cidade. Lisboa: Ulisséia, 1972.

MARICATO, E. Metrópole na periferia do capitalismo. São Paulo: Hucitec, 1996.

MONTANER, J. M. Después del movimiento moderno arquitectura de la segunda mitad del sigli XX. Barcellona: Editorial GG., Arquitectura Contextos, 1993.

RANDOLPH, R. Determinações estratégicas e potencialidades de transformação do Programa Favela-Bairro. Rio de Janeiro: IPPUR, 1996.

RIZEK, C. S.; VICENTINI, Y. Neoliberalismo e políticas sociais compensatórias na América Latina. In: ENCONTRO NACIONAL DA ANPUR, 6., 1996, Brasília. Anais... Brasília.

SILVA BEGA, M. T. Planejamento - espetáculo e a construção do cidadão consumidor: as imagens de Curitiba. Curitiba, 1997. Mimeografado.

SOUZA SANTOS, B. Pela mão de Alice - o social e o político na pós-modernidade. São Paulo: Cortez, 1995.

. Introdução a uma ciência pós- moderna. Rio de Janeiro: Graal, 1989.

VATTIMO, G. El fin de la modernidad. Barcelona: Gedisa Editorial, Espanha, 1985.

VICENTINI, Y. Teorias da cidade e as reformas urbanas contemporâneas. Desenvolvimento e Meio Ambiente, Curitiba: UFPR, n. 03, jan./jun. 2001. 